\title{
2006-2583: SIMULATION OF PARTICULATE MATTER DISTRIBUTION OVER IOWA
}

\section{Svetlana Korotkova, University of Northern Iowa}

Graduate student

Education:

- 2005-current, Doctoral of Industrial Technology (DIT) Student, UNI. • M.S. in Environmental Science (2005), University of Northern Iowa, Cedar Falls, Iowa • B.S. and M.S. in Environmental Engineering and Protection (2001), Moscow State Institute of Steel and Alloys (Technological University), Moscow, Russia

Research Interests: • Environmental Science, Engineering and Industrial Technology Issues; • Pollution Simulation and Modeling; • Waste reduction • Pollution Prevention.

\section{Alan Czarnetzki , University of Northern Iowa}

Professor of Meteorology

Education:

- Ph. D. Meteorology (1992), University of Wisconsin-Madison • M. S. Meteorology (1986), University of Wisconsin-Madison • B. S. Meteorology (1984), University of Wisconsin-Madison

Research Interests:

- Middle latitude cyclones (dynamic and synoptic meteorology) • Thunderstorm phenomena (mesoscale dynamics) - Air quality - Meteorological decision support systems that can be used by decision makers, planners, and emergency managers charged with protecting communities in the path of potentially adverse weather.

\section{Keith McCready, University of Northern Iowa}

Software Engineer, currently with Rockwell Collins, Inc.

Education:

B. S. Computer Science (2003), University of Northern Iowa Interests:

- Real-Time Embedded Systems • Autonomous model aircraft • Distributed computer systems 


\title{
Simulation of Particulate Matter Distribution over Iowa
}

\begin{abstract}
This paper discusses a Weather Research and Forecast Model with chemical processes (WRF-CHEM) that was used to simulate the transport of particulate matter with diameter less than 2.5 micrometers (PM 2.5) over Iowa. These forecasts were compared to surface monitor measurements of PM 2.5 concentration and measurements of aerosol optical depth from the MODIS (Moderate Resolution Imaging Spectradiometer) sensor. Several episodes of high PM 2.5 concentrations during the years $2000-2003$ were examined. A Box Model was used to estimate the relative size of transport processes to emissions and particulate mass tendency.
\end{abstract}

Simulations of atmospheric conditions demonstrated overall satisfactory agreement with observed data, suggesting that WRF-CHEM could be used to simulate pollution movement and mixing. The average linear correlation coefficients between simulated and measured PM 2.5 concentrations for three cases examined more closely were found to be greater than those reported in the literature. Satellite and surface observations appeared to be in reasonable agreement with model predictions. Nevertheless, various uncertainties in PM simulation have been identified. Substantial underforecasting of surface PM 2.5 concentration was found. The Box Model budgets for particulate matter revealed relatively large residual components. Results of the present research may serve as a basis for further work with WRFCHEM on the dispersion of other pollutants (e.g., nitrogen compounds) and the contribution from adjacent states in the environmental engineering.

\section{Introduction}

Numerous air pollution episodes are characterized by particulate matter (PM) suspended in the troposphere. Though human activities have emitted particles into the atmosphere since pre-industrial times, emissions have increased notably since the $1950 \mathrm{~s}^{1}$ ). The increased aerosol concentration not only changes the environment (for example, alters visibility), but also influences the earth-atmosphere energy budget. Aerosols directly absorb and backscatter incoming solar radiation and, by serving as cloud condensation nuclei, indirectly modify the optical properties and lifetimes of clouds. This has an impact on global and regional climate. Moreover, fine particulate matter can lead to adverse health effects. For these reasons, aerosol studies are highly important ${ }^{2,3}$.

The goal of this study is to evaluate a budget for fine particulate matter with diameter less than 2.5 micrometer (hereafter, PM 2.5) over Iowa. A Box Model is used to examine the relative size of transport processes to emissions and particulate mass tendency. The study of particulate matter dispersion is a complicated problem, involving both meteorological factors (such as wind speed and direction, turbulence, radiation, clouds, and precipitation) and chemical processes (such as deposition and transformation). Correspondingly, the physical consistency of numerical simulations can be the most appropriate way to examine the complex interactions of the meteorology and chemistry involved in air quality issues. The source of data for this study is the Weather Research and Forecast Model with Chemical processes (WRF-CHEM Model). The paper examines aerosol episodes (instances when concentrations of PM 2.5 are close to or higher than the National Ambient Air Quality Standards) during the years 2000 - 2003, and compares the WRF-CHEM simulations to satellite and surface data. Results 
of this research may serve as the basis for future work with WRF-CHEM on the dispersion of other pollutants (e.g., nitrogen compounds) and the contribution of adjacent states to the air quality in Iowa.

\section{Methodology of the study}

The present work uses high resolution numerical model data as the basis for the budget study of PM 2.5. Meteorological data and chemistry profiles served as input to WRF-CHEM. These data were initialized by the model. WRF-CHEM then produced 24-hour simulations, which served as input to the Box Model.

The paper examines several episodic aerosol events characterized by elevated particulate concentration (i.e., relatively high concentration of particulates) from the years $2000-2003$ in Iowa. Locations of hourly PM 2.5 monitoring sites in Iowa are presented in Figure 1. Days characterized by elevated PM 2.5 concentrations according to the both satellite and surface observations are presented in Table 1 .

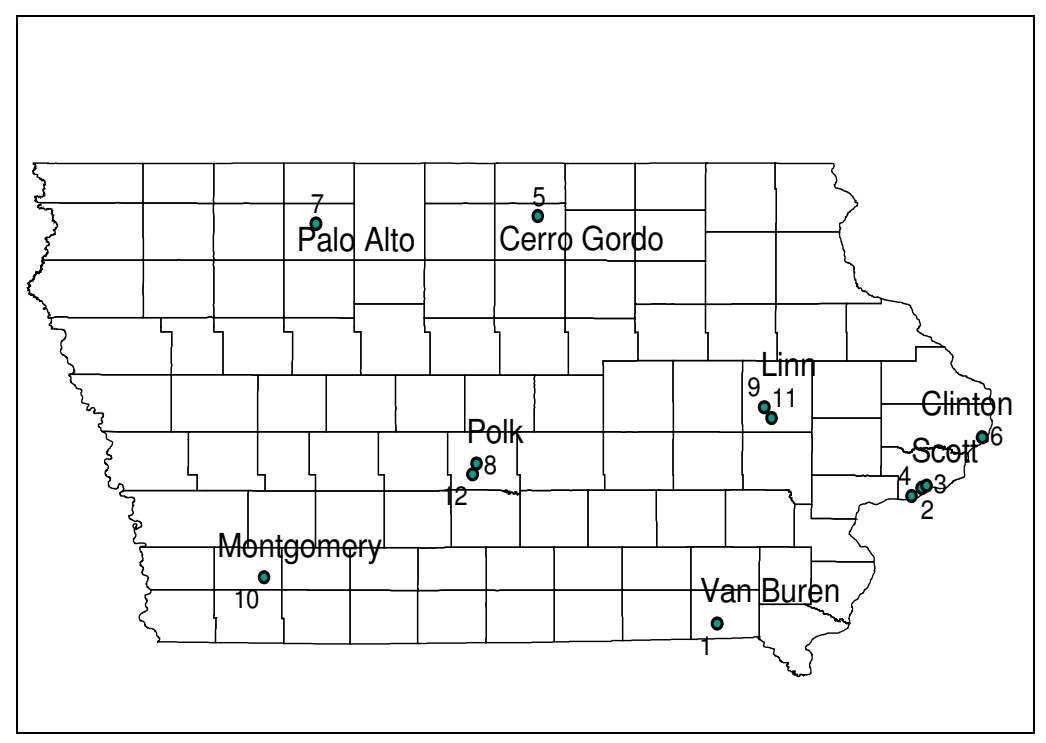

Figure 1. Locations of hourly PM 2.5 monitoring sites in Iowa by county ${ }^{4}$. 
Table 1: Days of elevated aerosol events detected with both satellite (MODIS Terra and Aqua sensors) and surface observations ${ }^{4}$.

\begin{tabular}{|l|l|l|l|l|l|l|}
\hline \multirow{2}{*}{ Month } & \multicolumn{1}{|c|}{2000} & \multicolumn{2}{c|}{2001} & \multicolumn{2}{c|}{2002} & \multicolumn{2}{c|}{2003} \\
\cline { 2 - 7 } & Terra & Terra & \multicolumn{1}{c|}{ Terra } & \multicolumn{1}{c|}{ Aqua } & Terra & Aqua \\
\hline June & & & 23,24 & & & \\
\hline July & 8 & & 8,17 & 8,17 & & \\
\hline August & 21,26 & 8 & 31 & 31 & 14 & \\
\hline September & & & $1,9,28$ & $1,9,28$ & 9 & \\
\hline
\end{tabular}

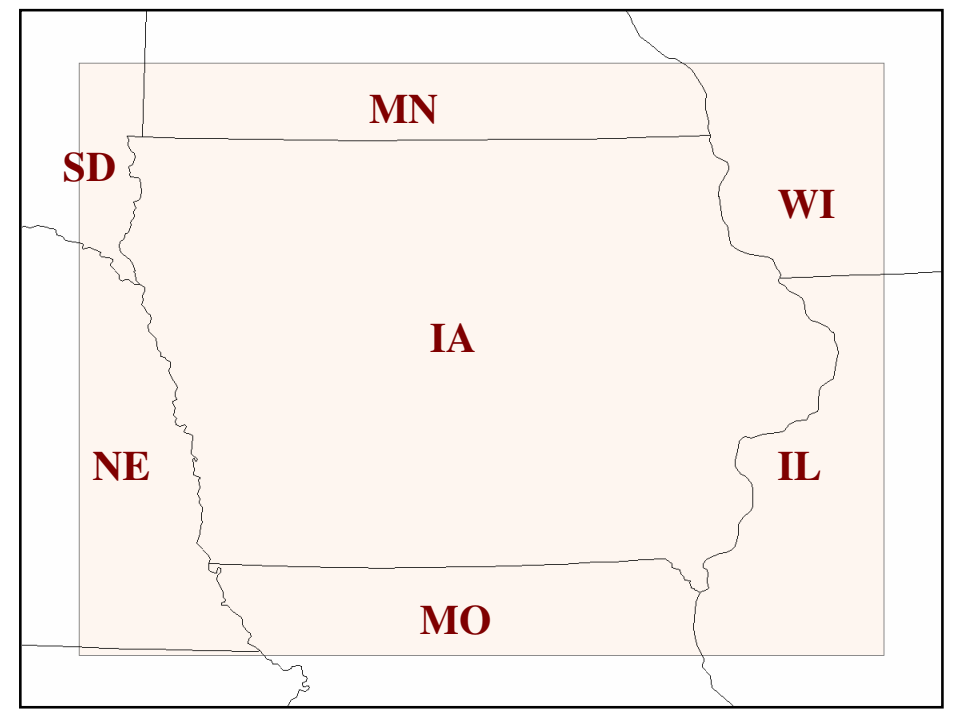

Figure 2. The WRF-CHEM domain used for the study.

A domain over Iowa was used for this study, yielding a grid of $47 \mathrm{X} 35$ points (west to east and north to south dimensions, respectively). The domain was selected so that it covers Iowa and parts of neighboring states (Figure 2). The distance between grid points (grid spacing) is $15 \mathrm{~km}$. The numerical grid of the domain is centered at $93.35^{\circ} \mathrm{W}$ longitude and $42.00^{\circ} \mathrm{N}$ latitude. The number of vertical levels is 31 and extends up to $11,762 \mathrm{~m}$ with vertical spacing gradually increasing from bottom to top.

A box model approach is used to examine the budget for PM2.5 within a fixed volume of the atmosphere over Iowa (Figure 3). In this model, the tendency of PM2.5 mass within the box results from transport across the lateral and vertical faces of the box, emissions within the box and removal by deposition and transformation. The net transport across all faces of the box that leads to a mass increase is known as mass flux convergence. This paper did not examine the deposition or transformation components of the budget. Instead, a budget residual term is used to estimate the combined size of these terms. 
In principle, there is transport across all faces of the box, i.e., the lateral faces, the top and bottom. In this study, the tropopause (earth surface) was used as the top (bottom) of the box. That allowed for the assumption of no vertical transport across the top of the box, and transport across the bottom of the box would only occur through emission and deposition.

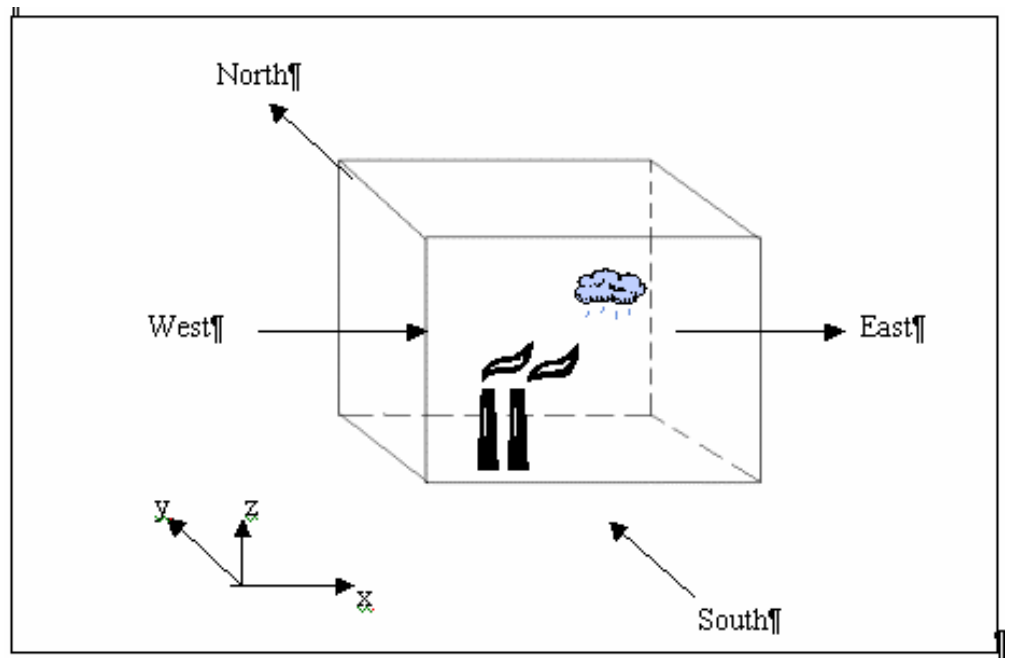

Figure 3. Schematic representation of aerosol transport in the Box Model.

\section{Results}

Colorized maps of predicted aerosol concentration for the 8 August 2001 (Figure 4), 8 July 2002 (not shown) and 9 September 2002 [not shown] were compared with satellite data retrieved from Terra and Aqua MODIS sensors. Fig. 4 illustrates colorized maps of predicted vertically integrated PM 2.5 concentration (top) and satellite images of aerosol optical depth (AOD) representing non-dimensional measure of the amount of aerosols in atmospheric column (bottom). Although, predicted PM 2.5 concentration was greatest over the northeast portion of the domain while the observed AOD was greater in the southeast, WRF-CHEM did capture the broad pattern, i.e. relatively high values of PM over the eastern part of Iowa.

Time series of predicted and observed surface concentration of PM 2.5 over 24-hour periods were examined for three episodes (8 August 2001 [Figure 5], 8 July 2002 [not shown] and 9 September 2002 [not shown]). Evaluation of these data demonstrates relatively good correspondence between observed and modeled trends, but not in the concentrations.

Vertical profiles of predicted PM 2.5 concentrations, calculated every 6 hours, have been produced for the August 2001 (Figure 6), July and September 2002 (not shown) aerosol events. Variations in profiles demonstrated an increase of concentration with height in the near surface levels (up to $1000 \mathrm{~m}$ ) during the night and morning hours (Figure 6), with a general decrease of PM concentration with increasing height. The profiles suggest the formation of the atmospheric mixed layer (the lowest part of the atmospheric boundary layer, which is characterized by mixing processes) observed in the afternoon. Pollutant concentration is typically greatest in the mixed layer. The depth of the mixed layer from radiosonde data (FSL/NCDC, 2005) of $950 \mathrm{~m}, 900 \mathrm{~m}$ and $900 \mathrm{~m}$ for the 8 August 2001, 8 July 2002 and 9 September 2002 events, respectively, is consistent with information from WRF-CHEM vertical 
profiles of PM. However, the profiles are also puzzling in that they display spikes of high aerosol concentration at the upper atmospheric levels. These could be explained by transport of PM at upper atmospheric levels.

In order to gauge the accuracy of WRF-CHEM simulations of atmospheric conditions, predicted and observed winds and temperature were compared for the 8 August 2001 aerosol episode. While a limited comparison (for one case) between predicted and observed meteorological data has been done and some forecast errors (mostly related to evaluation of temperature and dew point) were found, the forecast meteorological fields compared well to observations. This underscored that the predicted meteorology could be used to simulate pollution movement and mixing.

The results of the 24-hour WRF-CHEM forecasts were analyzed with the Box Model. The Box Model budget for particulate matter calculates mass tendency, emissions, and mass flux convergence over the domain depicted in Figure 2. Figures 7-9 display time series of the Box Model budget for these events.

The residual component is calculated by subtracting the mass flux convergence and emissions from the mass tendency. In all cases, the residual component is relatively large (on average about $1500 \mathrm{~kg} / \mathrm{s}$ ). Moreover, the residual term is both positive and negative during the model runs, which may be explained by deposition and gas-to-particle-conversion acting as sinks and sources, respectively.

\section{Conclusion}

An analysis of predicted and observed PM 2.5 concentrations over Iowa during several aerosol episodes in 2000 - 2003 and analyses of aerosol distribution patterns have been presented. Budgets for PM 2.5 based on the Box Model approach have also been examined.

Linear correlation coefficients between simulated and measured particulate matter concentration at the surface ranged from 0.01 to 0.82 . The average correlation coefficients are higher than those found in the literature. Qualitative analysis of WRF-CHEM simulations showed substantial underforecasting of PM 2.5 concentration, which is consistent with results of previous studies. Predicted concentrations on average ranged from 0.005 to $0.103 \mu \mathrm{g} / \mathrm{m}^{3}$, while those measured by surface monitors were in the range of 17.0 to $41.7 \mu \mathrm{g} / \mathrm{m}^{3}$. Overall, WRF-CHEM did capture the broad pattern of PM concentration indicated by satellite and surface data.

While minor forecast errors in WRF-CHEM meteorology were produced, comparison of predicted and observed meteorological data demonstrated overall satisfactory agreement. Correspondingly, since the model is found to simulate the atmospheric processes well, it is reasonable to assume that it would also correctly simulate the transport of pollutants, which is a significant component of the mass budget.

Vertical profiles of predicted PM 2.5 appeared to be in a good agreement with day- to-night variations in the boundary layer structure. However, spikes in forecast aerosol concentration at the upper atmospheric levels, were also indicated. 


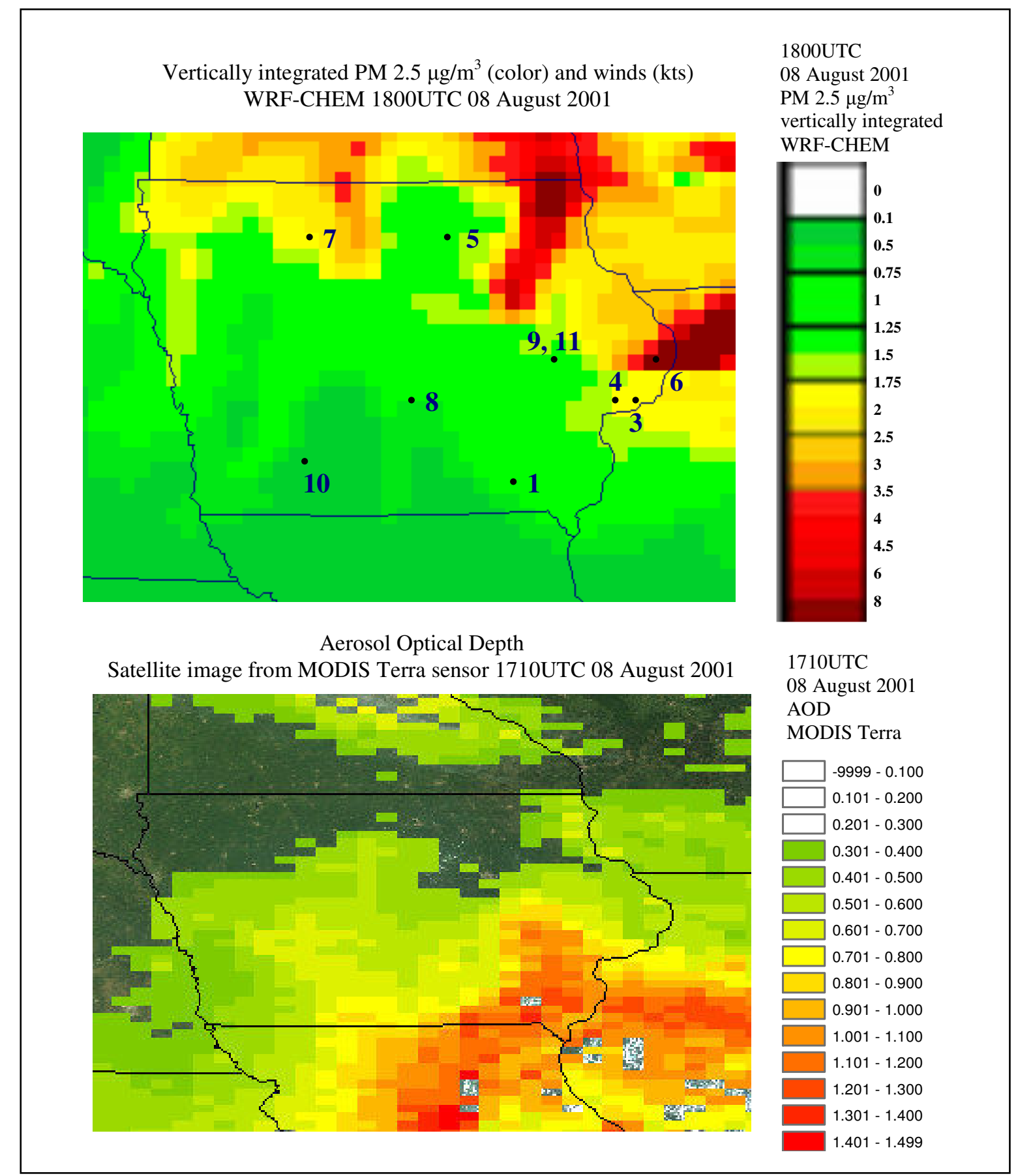

Figure 4. Predicted (WRF-CHEM) vertically integrated PM 2.5 concentration (top) and satellite (MODIS Terra sensor) aerosol optical depth (AOD) (bottom), 8 August 2001. 

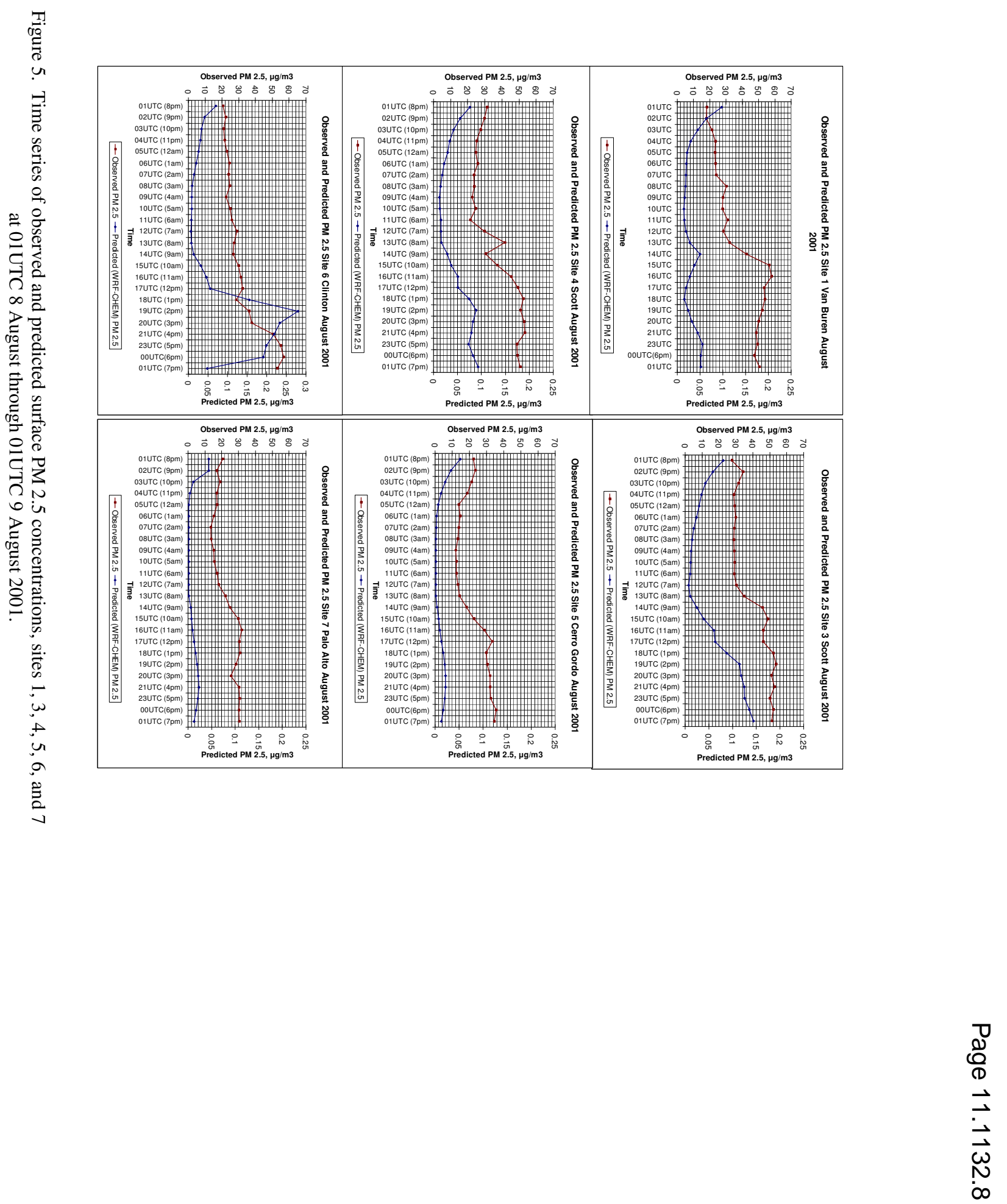

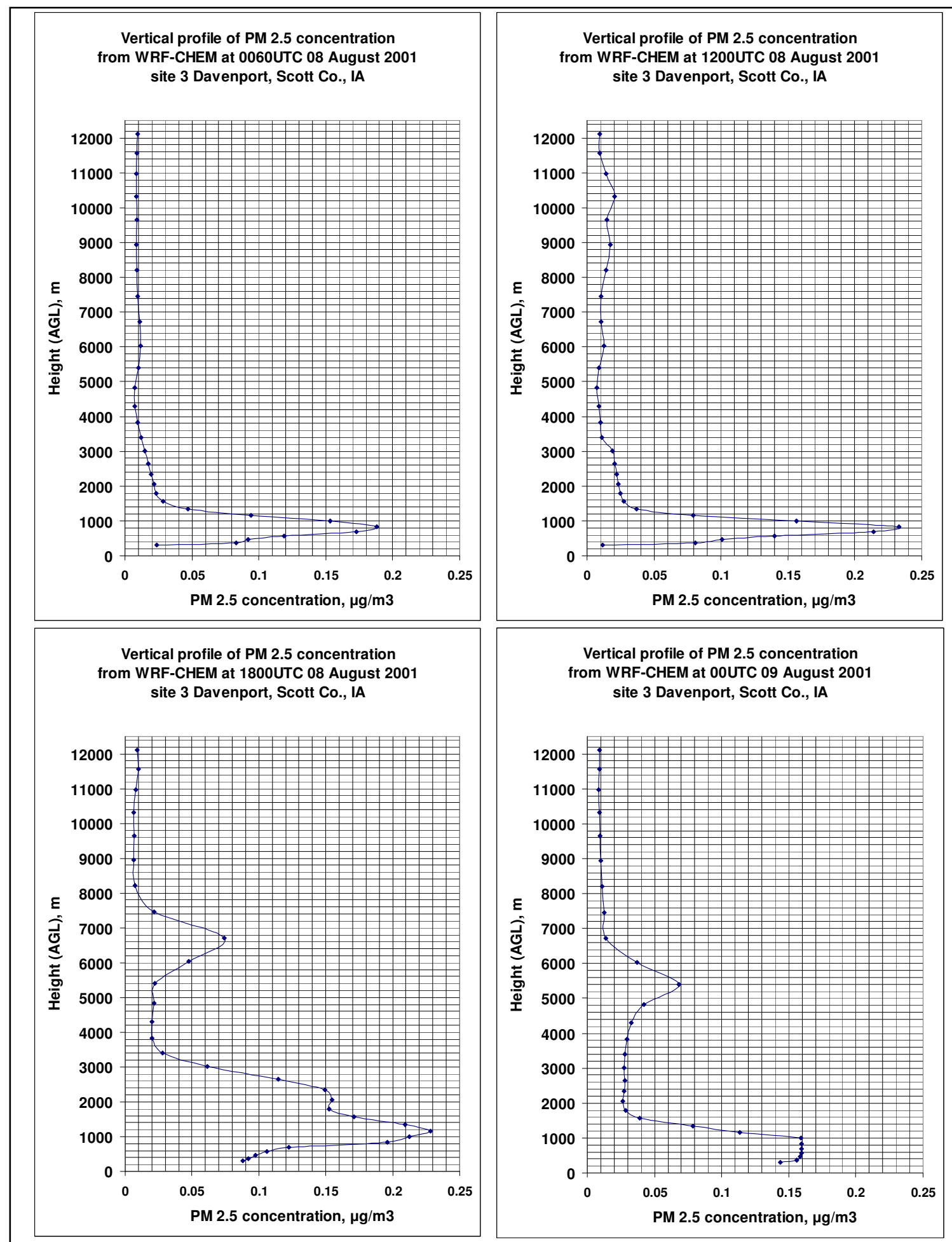

Figure 6. Vertical profiles of predicted PM 2.5 concentration at 6, 12, 18 UTC 8 August 2001 and 00UTC 9 August 2001 (site 3, Davenport). 

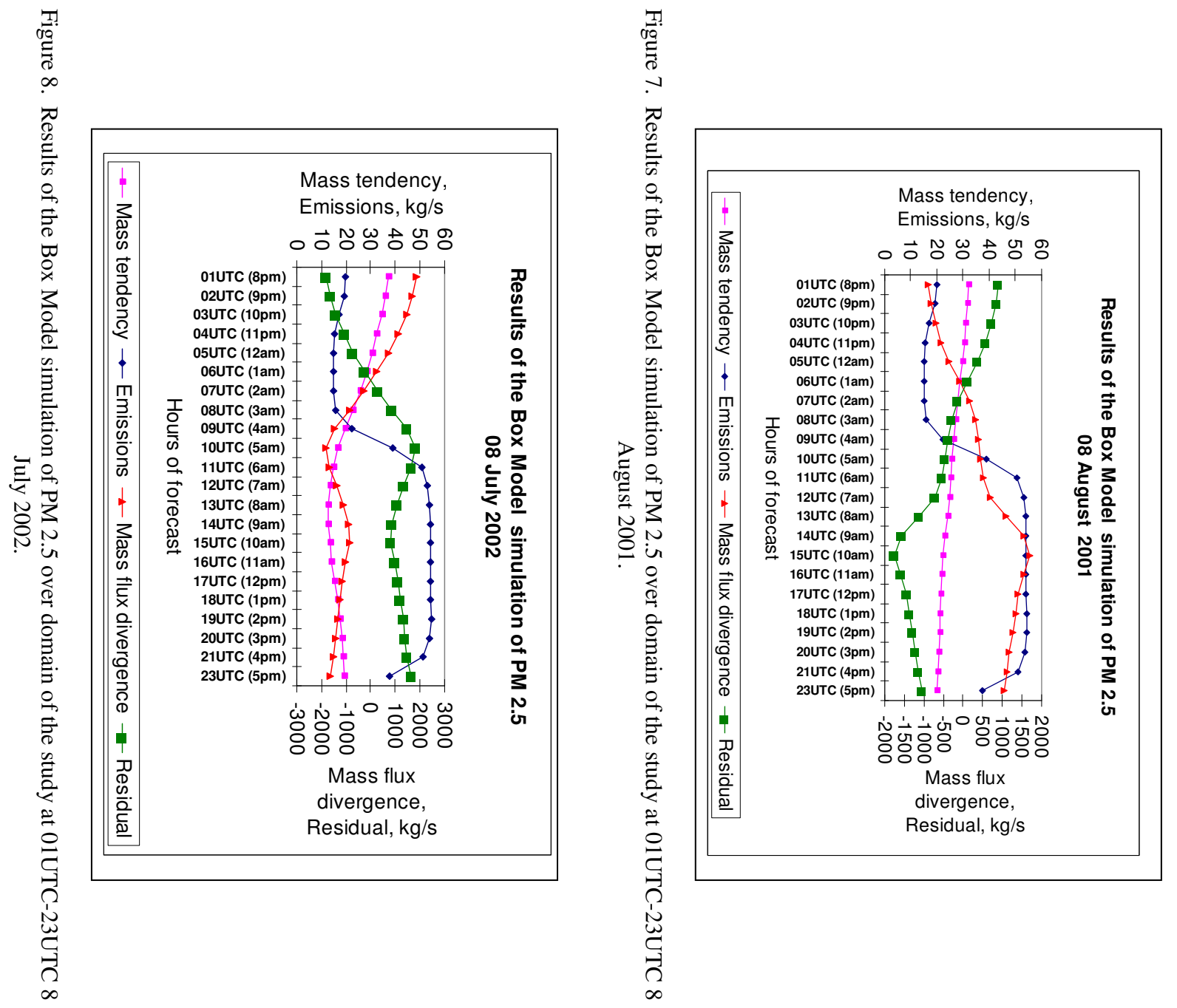


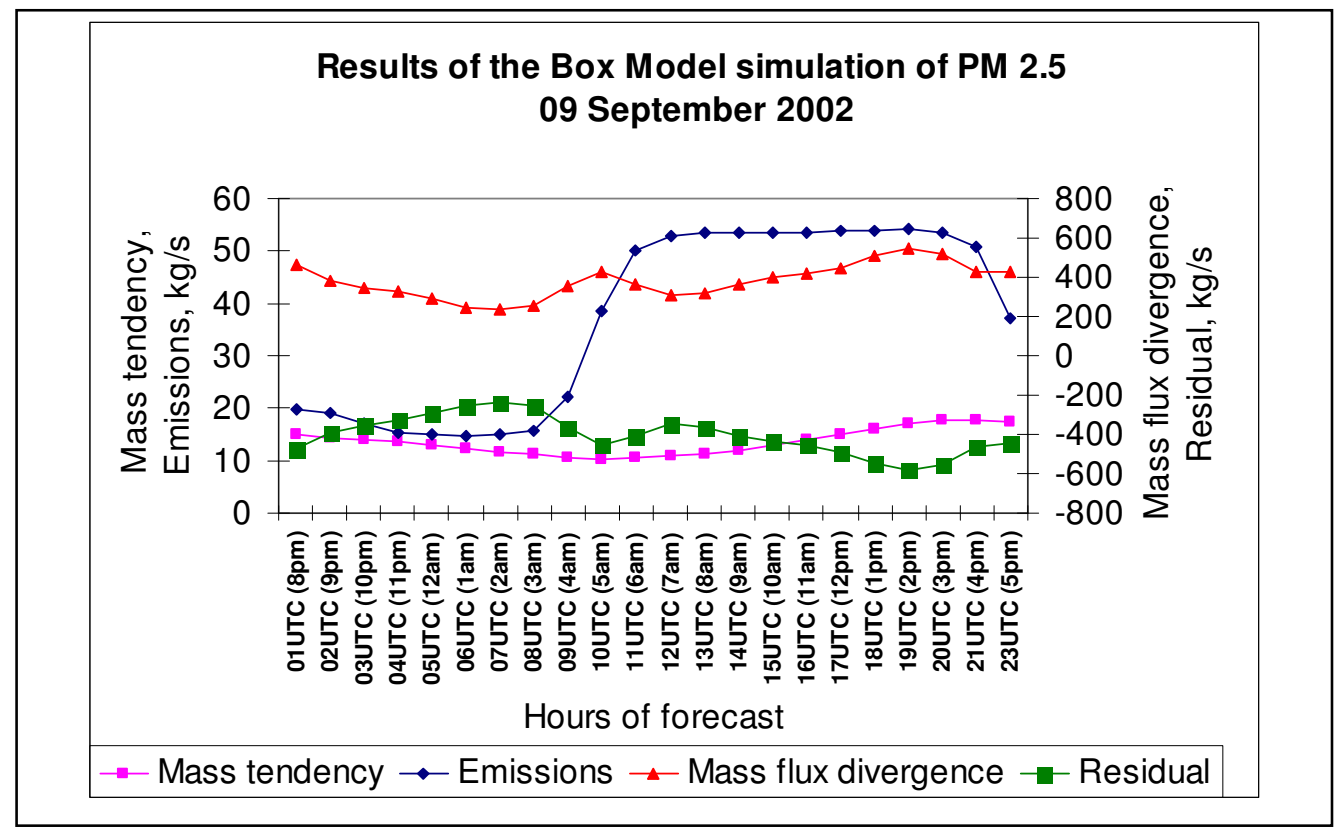

Figure 9. Results of the Box Model simulation of PM 2.5 over domain of the study at 01UTC-23UTC 9 September 2002.

Emissions from WRF-CHEM displayed a remarkably similar time evolution for all three cases. This may be the result of the specific way that emissions information is used by the WRF-CHEM. The mass tendency and mass flux convergence of PM 2.5 have been found to be reasonable. The residual component of PM 2.5, which estimates the net effects of deposition (sink processes) and gas-to-particle conversion (sources), was found to be negative and positive during the simulations and was characterized by relatively large values. The changes in residual sign provide some indication of when one dominant mode yields its effect to the other (i.e., deposition (gas-to-particle conversion) contributes to negative (positive) residual).

Difficulty in obtaining the emissions algorithm used by WRF-CHEM prevented this project from completely evaluating the emissions term of the budget. It is also possible that this version of WRFCHEM is not mass conservative with respect to PM 2.5. WRF-CHEM might benefit from more sophisticated emissions data.

Results of this study underscore the importance of coupling atmospheric pollutants with meteorological information in air quality forecasting, and may serve as the basis for further work with WRF-CHEM on the dispersion of other pollutants (e.g., nitrogen compounds) and the contribution of adjacent states to air quality in Iowa.

The WRF/CHEM can be used in environmental engineering education as a tool capable to conduct real time simultaneous prediction of air quality and weather. The model can make forecast simulations of climate, transport of chemical species such as ozone, UV radiation, and aerosols. As a result, it can help to get a better understanding of air quality issues and in learning process overall. 
There are a number of interesting possibilities for the students to be involved with the WRF-CHEM model application as a part of educational experience. Using the WRF-CHEM, students will have an opportunity to collect air quality data, run simulations in class setting, interpret, evaluate and present the results of their research. The educational applications of the WRF-CHEM are described in more detail below.

The WRF-CHEM model can potentially be incorporated into currently taught environmental classes at the college level of education. For example, the four potential major curricular areas to conduct air quality investigations correspond to the following classes: "Air Quality", "Meteorology", "Elements of weather", and "Weather Analysis and Forecasting". Both the graduate and undergraduate students taking the abovementioned classes could be exposed to the training regarding the WRF-CHEM.

The WRF-CHEM could be brought into the classrooms during the lectures. It could be incorporated in class such as "Air Quality" in the section that discusses the transport and dispersion models. The teacher could explain WRF-CHEM's major purpose and basics of operation. This model also could be included in students' home works or small class projects. For example, the students could be trained to forecast climatic changes resulting from predicted trends in pollutant dispersion. The WRF-CHEM could be a part of extra-curriculum activities to be done by small groups of undergraduate students as well as by a graduate student alone.

The Air Quality, Meteorology, Weather Analysis and Forecasting, and Elements of Weather students would have the opportunity to use the version of the WRF-CHEM model installed on on-campus computers located in class labs. The instructor would provide them with access to numerous on-line air quality databases. The simulations and forecasting of the pollutants could be conducted under the supervision of instructor. The resulting forecasts are to be analyzed and summarized in reports/papers by students. The research activities could lead to students' presentations during classes. In some cases the projects could be elaborated and include long-term simulations of several pollutants. This type of forecasts might serve as a foundation of a master's thesis or doctoral dissertation subject.

\section{References}

[1] Luo, Y., Lu, D., He, Q., Li, W., and Zhou, X., 2000. Characteristics of atmospheric aerosol optical depth variation over China in recent 30 years. Chinese Science Bulletin Vol. 45 (14), 1328-1333.

[2] ARIC (Atmosphere climate and environment), 2005. Atmospheric aerosols and climate change. Available from: http://www.ace.mmu.ac.uk/Resources/Fact_Sheets/Key_Stage_4/Climate_Change/04.html

[3] NASA (National Aeronautics and Space Administration), 2005. NASA's facts online. Available from: http://oea.larc.nasa.gov/PAIS/Aerosols.html

[4] Korotkova, O.A., 2005. M.S. Thesis. Measurements of atmospheric aerosols over Iowa. University of Northern Iowa, in press. 